\title{
Computer Use among Different Gender Medical Students in Inner Mongolia Medical University in China
}

\author{
Lan Wang ${ }^{*}$, Zhuang Su${ }^{1 *}$, Baofeng Chi ${ }^{*}$, Ying Yang ${ }^{1}$, Chengcheng Yin ${ }^{2}$, Jiao Zhou ${ }^{3}$, \\ Yuan Xia', Juan Sun"\# \\ ${ }^{1}$ Inner Mongolia Medical University, Hohhot, China \\ ${ }^{2}$ Beijing Yisheng Care Medical Technology Co., Ltd., Beijing, China \\ ${ }^{3}$ Business College of Shanxi University, Shanxi, China \\ Email:"2573479397@qq.com
}

Received 10 December 2015; accepted 31 January 2016; published 3 February 2016

Copyright (C) 2016 by authors and Scientific Research Publishing Inc.

This work is licensed under the Creative Commons Attribution International License (CC BY).

http://creativecommons.org/licenses/by/4.0/

(c) (i) Open Access

\begin{abstract}
Objective: The purpose of this study was to evaluate the difference of computer use and the negative effects for different gender in the Medical University of Inner Mongolia. Methods: A crosssectional census was conducted on medical students on campus in 2013. Descriptive results were expressed as percentage, prevalence and means \pm S.D. Gender differences of using computer time and using computer purpose for male and female students were analyzed by chi-square test. Results: Students using computer more than three hours per day had higher headache prevalence and poor academic performance prevalence than that less than three hours per day. The prevalence of male students using computer more than three hours per day was significantly higher than female students $\left(\chi^{2}=72.92, p<0.001\right)$. The prevalence of male students using computer for playing games was more than 3 times higher than female students $\left[50.2 \%\right.$ vs $16.1 \%, \chi^{2}=783.70, p$ $<0.001)$. Conclusion: Using computer for long time brings more students headache and poor academic performance. These results suggest that using computer time reasonably and learning efficiently among university students are necessary, especially for male.
\end{abstract}

\section{Keywords}

Different Gender, Computer Use, Purpose, Headache, Academic Performance

\footnotetext{
${ }^{*}$ Contributed equality to the paper.

"Corresponding author.
}

How to cite this paper: Wang, L., Su, Z., Chi, B.F., Yang, Y., Yin, C.C., Zhou, J., Xia, Y. and Sun, J. (2016) Computer Use among Different Gender Medical Students in Inner Mongolia Medical University in China. Open Journal of Epidemiology, 6, 23-27. 


\section{Introduction}

The harm of using computer long time has been widely studied. Young adults and adolescents who lack of self-control were the most vulnerable groups regarding the length of time they spend on use computer [1]-[3], so they are more likely to suffer a negative impact. At computer terminals not only may result in neck pain and headaches [4] but also with the amount of time that students spend on the computer rising may have an impact on academic performance [5]. Other studies also confirmed that there were significant differences between male and female students concerning computer use for personal purposes for a variety of uses [6] and health related issues caused by computer use.

Therefore, the purpose of this study was to evaluate the characteristic of computer use and the negative effects of the different gender in the Medical University of Inner Mongolia. These results will help university administrators provide more healthy ways to use computer for male and female students and let students use computer time reasonable and learn efficiently.

\section{Method}

A cross-sectional study design formed the basis of this study which was conducted among college students who resided on campus at Inner Mongolia medical university in China. A member of our study group explained the purpose of the survey, and the privacy protection policy for personal and enrollment data, and checked completed questionnaires. Participants returned the completed anonymous self-administered questionnaire in a sealed envelope to members of our study group [7]. Self-administered questionnaire form was prepared to capture the medical school students' behavior of using computer, demographics and status of headache, academic performance. Using computer included two sections. The time of using computer every day: less than three hours or more than three hours; The purpose of using computer: search study information, play games, other (Chat, e-mail, shopping).

All the analysis is based on the computer use of different male and female students' characteristics. Descriptive results were expressed as percentage, prevalence and means \pm S.D. Gender differences of using computer time and using computer purpose for male and female students were analyzed by chi-square test. Data were recorded using EpiData 3.1. Data analysis was conducted using SPSS Statistical Software for Windows (SPSS version 13.0) (IBM, Chicago, Illinois), with a significance level of $p<0.05$.

The Inner Mongolia Medical University Ethics Committee approved the current study prior to the census. Participation in the census was voluntary and informed consent was implied if students completed and returned their questionnaire.

\section{Result}

A total of 6046 medical students completed the questionnaire in the census. The mean age of students were $21.05 \pm 1.47$. In total, there were 6012 (99.4\%) students using computer every day.

The prevalence of male and female students using computer time in Inner Mongolia Medical University is shown in Figure 1 the prevalence of male students using computer more than three hours per day was significantly higher than female students $\left(\chi^{2}=72.92, p<0.001\right)$. The prevalence of female students using computer less than three hours per day was significantly higher than male students $\left(\chi^{2}=71.99, p<0.001\right)$.

The prevalence of the purpose for students using computers were shown in Figure 2. More than half of students use computer for searching information both in male and female students (56\%, 55.4\%). The prevalence of male students using computer for playing games was more than 3 times higher than female students $(50.2 \%$ vs $16.1 \%, \chi^{2}=783.70, p<0.001$ ). The prevalence of female students using computer for other purpose was more than $20 \%$ higher than male students $\left(69.6 \%\right.$ vs $\left.47.3 \%, \chi^{2}=258.58, p<0.001\right)$.

Figure 3 shows headache prevalence for male and female students with different time of using computer. Students using computer more than three hours per day had higher headache prevalence than that less than three hours per day both in male $\left(39.4 \%\right.$ vs $\left.48.6 \%, \chi^{2}=10.63, p=0.001\right)$ and female $\left(49.2 \%\right.$ vs $55 \%, \chi^{2}=7.54, p=$ 0.006).

Figure 4 shows poor academic performance prevalence for male and female students with different time for using computer. The prevalence of poor academic was higher for students using computer more than three hours per day compared with students using computer less than three hours per day both in male $\left(11.7 \%\right.$ vs $17.1 \%, \chi^{2}$ $=7.90, p=0.005)$ and female $\left(4.1 \%\right.$ vs $\left.7.3 \%, \chi^{2}=13.92, p<0.001\right)$. 


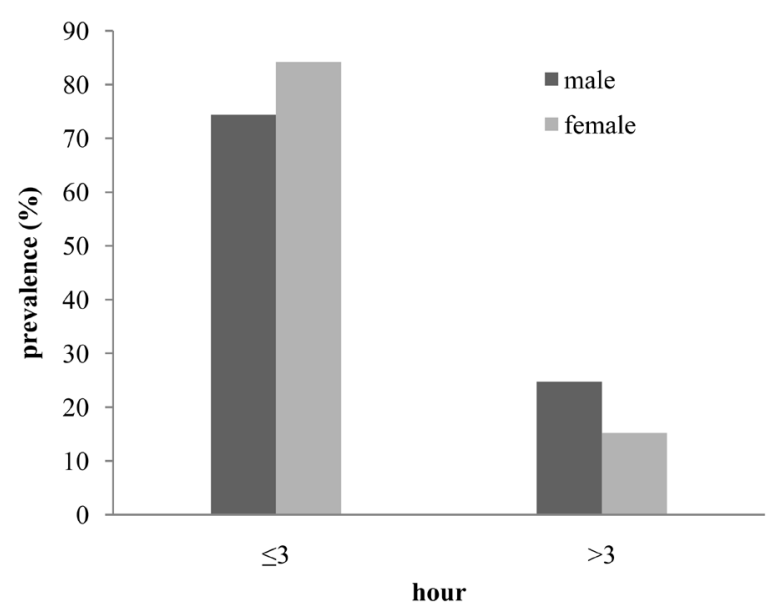

Figure 1. The prevalence of students using computer time in Inner Mongolia Medical University.

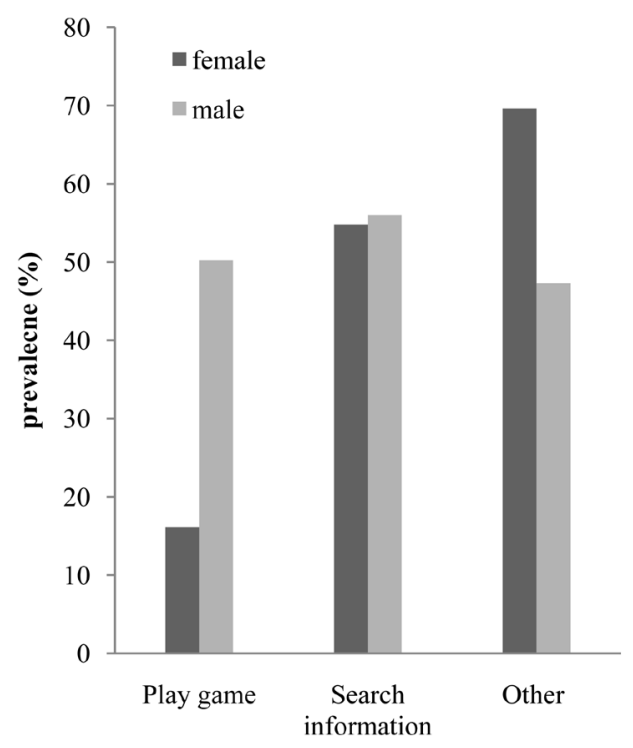

Figure 2. The prevalence of the purpose for students using computers in Inner Mongolia Medical University.

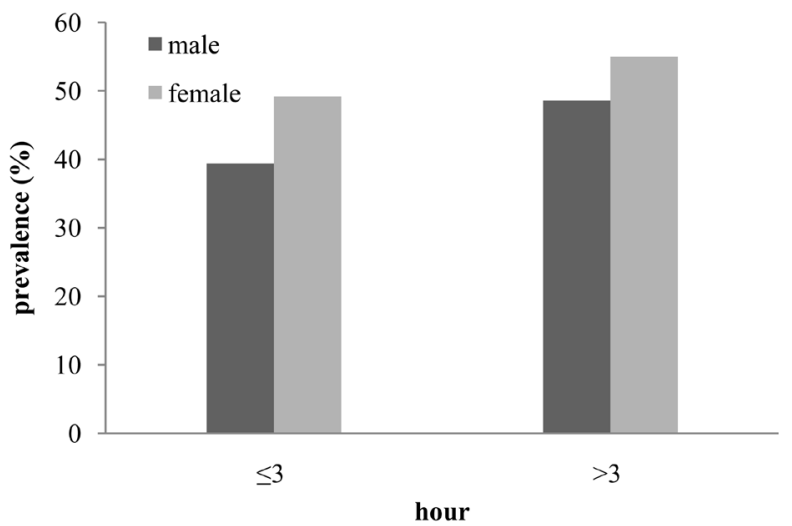

Figure 3. Headache prevalence for students with different using computer time in Inner Mongolia Medical University. 


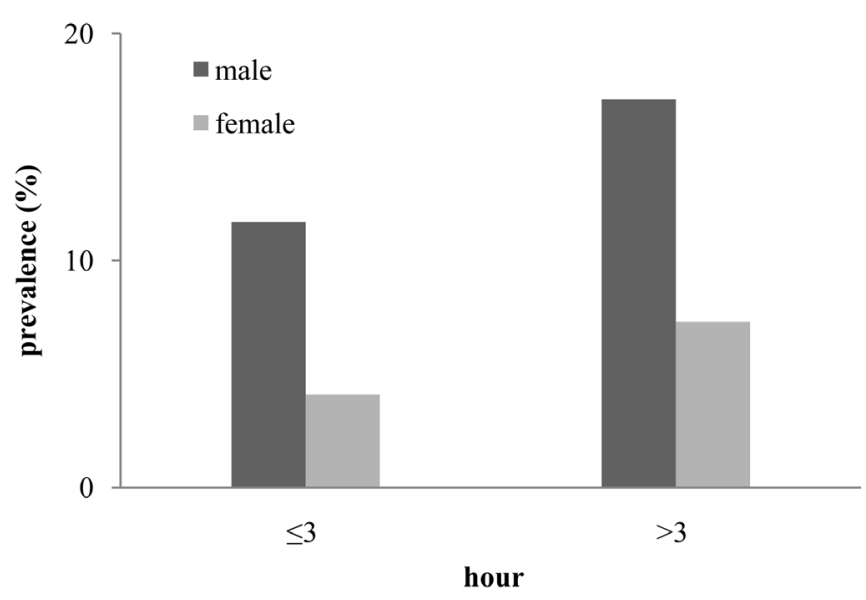

Figure 4. Poor academic performance prevalence for students with different using computer time in Inner Mongolia Medical University.

\section{Discussion}

Studies suggest that men use the computer longer than women, and they are also known to use it more for gaming, entertainment [2] [8] [9]. Consistent with those studies, we found that the prevalence of male students using computer more than three hours per day was 1.5 times higher than female students and half of the male students using computer for playing games. For female students, nearly $70 \%$ of them using computer for chatting, emailing was higher than male students in our study, consistent with another study [5]. We also found that male students using computer more than three hours had the higher prevalence of poor academic performance than female students. Study of others revealed that long time computer use was the negative correlation with the academic achievement [10] and use computer for playing games alone to less socialization and impaired school performance [11] [12].

Our study also found that students using computer more than three hours had the higher prevalence of headache and the headache prevalence of female students was higher than male students. Studies revealed that excessive use of electronics (computer, television) devices proved to be a risk factor for headache [13] and sitting for lengthy periods at computer terminals may result in neck pain and headaches [4] [14].

\section{Conclusion}

In general, using computer for long time brings more students headache and poor academic performance. More male students use the computer to play games; more female students use computers for chat or e-mail. Therefore, the school management should provide the students more healthy ways to use computer, let students use computer time reasonable and learn efficiently, especially for male students.

\section{Acknowledgements}

The study was supported by the Natural Science Foundation of Inner Mongolia, China (grant No. 2013MS1193).

\section{References}

[1] Young, K.S. (2004) Internet Addiction: A New Clinical Phenomenon and Its Consequences. American Behavioral Scientist, 48, 402-415. http://dx.doi.org/10.1177/0002764204270278

[2] Durkee, T., Kaess, M., Carli, V., Parzer, P., Wasserman, C., Floderus, B., Apter, A., Balazs, J., Barzilay, S. and Bobes, J. (2012) Prevalence of Pathological Internet Use among Adolescents in Europe: Demographic and Health-Related Risk Factors. Addiction, 27, 2210-2222. http://dx.doi.org/10.1111/j.1360-0443.2012.03946.x

[3] Şaşmaz, T., Öner, S., Kurt, A.Ö., Yapıcı, G., Yazıcı, A.E., Buğdaycı, R. and Şiş, M. (2014) Prevalence and Risk Factors of Internet Addiction in High School Students. European Journal of Public Health, 24, 15-20. http://dx.doi.org/10.1093/eurpub/ckt051 
[4] Auvinen, J., Tammelin, T.S., Zitting, P. and Karppinen, J. (2007) Neck and Shoulder Pains in Relation to Physical Activity and Sedentary Activities in Adolescence. Spine, 32, 1038-1044. http://dx.doi.org/10.1097/01.brs.0000261349.94823.c1

[5] Hunley, S.A., Evans, J.H., Delgado-Hachey, M., Krise, J., Rich, T. and Schell, C. (2005) Adolescent Computer Use and Academic Achievement. Adolescence, 40, 12.

[6] Wasserman, I.M. and Richmond-Abbott, M. (2005) Gender and the Internet: Causes of Variation in Access, Level, and Scope of Use. Social Science Quarterly, 86, 252-270. http://dx.doi.org/10.1111/j.0038-4941.2005.00301.X

[7] Sun, J., He, Y., Liu, Z., Yan, W., Jiang, B., Wu, Y., Eshita, Y., Li, G., Zhang, Q. and Ying, Y. (2013) Factors Associated with Skipping Breakfast among Inner Mongolia Medical Students in China. BMC Public Health, 13, 42. http://dx.doi.org/10.1186/1471-2458-13-42

[8] Chou, C., Condron, L. and Belland, J.C. (2005) A Review of the Research on Internet Addiction. Educational Psychology Review, 17, 363-388. http://dx.doi.org/10.1007/s10648-005-8138-1

[9] Eow, Y.L., Wan, Z.B.W.A., Mahmud, R.B. and Baki, R. (2009) Form One Students' Engagement with Computer Games and Its Effect on Their Academic Achievement in a Malaysian Secondary School. Computers \& Education, 53, 1082-1091. http://dx.doi.org/10.1016/j.compedu.2009.05.013

[10] Tayfun, K., Recai, O., Selim, K., Omer Faruk, T. and Metin, H. (2004) How Medical Students Use the Computer and Internet at a Turkish Military Medical School. Military Medicine, 169, 976-979. http://dx.doi.org/10.7205/MILMED.169.12.976

[11] Gentile, D.A., Hyekyung, C., Albert, L., Timothy, S., Dongdong, L., Daniel, F. and Angeline, K. (2011) Pathological Video Game Use among Youths: A Two-Year Longitudinal Study. Pediatrics, 127, e319-e329. http://dx.doi.org/10.1542/peds.2010-1353

[12] Norris, T.L. (2010) Adolescent Academic Achievement, Bullying Behavior, and the Frequency of Internet Use. Proquest Llc, 112.

[13] Xavier, M.K.A., Pitangui, A.C.R., Silva, G.R.R., Beltrão, N.B., Araújo, R.C.D., Pitangui, A.C.R. and Silva, G.R.R. (2015) Prevalence of Headache in Adolescents and Association with Use of Computer and Videogames. Ciência \& Saúde Coletiva, 20.

[14] Peter, P., Gunnar, P., Allan, T., Tornqvist, E.W., Eva, H.R. and Monica, M. (2007) Computer Use, Neck and UpperExtremity Symptoms, Eyestrain and Headache among Female and Male Upper Secondary School Students. Scandinavian Journal of Work Environment \& Health Supplement, 33, 33-41. 